\title{
Artificial selection reveals the energetic expense of producing larger eggs
}

\author{
Joel L. Pick*, Pascale Hutter, Christina Ebneter, Ann-Kathrin Ziegler, Marta Giordano and Barbara Tschirren
}

\begin{abstract}
Background: The amount of resources provided by the mother before birth has important and long-lasting effects on offspring fitness. Despite this, there is a large amount of variation in maternal investment seen in natural populations. Life-history theory predicts that this variation is maintained through a trade-off between the benefits of high maternal investment for the offspring and the costs of high investment for the mother. However, the proximate mechanisms underlying these costs of reproduction are not well understood. Here we used artificial selection for high and low maternal egg investment in a precocial bird, the Japanese quail (Coturnix japonica) to quantify costs of maternal reproductive investment.
\end{abstract}

Results: We show that females from the high maternal investment lines had significantly larger reproductive organs, which explained their overall larger body mass, and resulted in a higher resting metabolic rate (RMR). Contrary to our expectations, this increase in metabolic activity did not lead to a higher level of oxidative damage.

Conclusions: This study is the first to provide experimental evidence for metabolic costs of increased per offspring investment.

Keywords: Life history evolution, Maintenance of variation, Cost of reproduction, Egg size, Maternal investment, Oxidative stress

\section{Background}

The environment experienced during early development can have significant and long-lasting consequences for an individual's phenotype $[1,2]$. Mothers are in a unique position to influence these early life conditions through, for example, the quantity and quality of resources they provide to their offspring [3]. Despite the positive effects of increased maternal investment on offspring fitness [3, 4], there is a large amount of variation in reproductive investment seen in natural populations [5, 6]. Life-history theory predicts that this variation is maintained by trade-offs between the benefits of increased investment for the offspring and the associated costs to the mother [7-9].

However, despite being a central tenant of life history theory, the mechanisms underlying these costs of reproduction are not well understood [10, 11]. Various mechanisms have been proposed to mediate the costs of reproduction. Costs may, for example, occur because females reallocate energy or resources from self-

\footnotetext{
* Correspondence: joel...pick@gmail.com

Department of Evolutionary Biology and Environmental Studies, University of Zurich, Winterthurerstrasse 190, 8057 Zurich, Switzerland
}

maintenance to reproduction [12]. If these reallocations cannot fully cover the increased energetic demands during reproduction, females have to increase their rate of energy conversion, through an increase in metabolic rate. This, in turn, can lead to a higher production of reactive oxygen species (ROS), produced in the mitochondria as a by-product of cellular respiration [13]. When not balanced by antioxidant defences, high levels of ROS are associated with cellular damage, referred to as oxidative stress [13], which has been proposed to be a key mediator of life-history trade-offs [14, 15]. Furthermore, an increased energetic demand may lead to extended food searching and so a higher predation risk $[16,17]$.

To date, most studies that explored the costs of reproduction, and in particular the costs of per offspring investment, are correlative [15] and therefore cannot reveal trade-offs [18]. In birds, and especially in precocial species that do not show extensive parental care after hatching, per offspring maternal resource investment is reflected in the size of the egg [19], which varies considerably in natural populations [20]. Although egg production 
per se is known to be an energetically demanding process $[12,21]$, few studies have explicitly quantified the costs of increased per offspring investment and those that have mainly focused on egg size-number trade-offs, for which there is little evidence [22-25].

Maternal egg investment (i.e. per offspring investment) is notoriously difficult to alter experimentally and, to our knowledge, no study has manipulated maternal egg investment and examined the costs to the mother. To address this gap, we established artificial selection lines for high and low maternal egg investment in a precocial bird, the Japanese quail (Coturnix japonica). Through artificial selection, we experimentally manipulated egg size, producing females that differ genetically in how much they invest in their eggs (relative to their body size). This selection resulted in a correlated response in resource investment (dry egg components), but there was no evidence for a trade-off with the number of eggs laid [24]. Here we show that the mothers' reproductive organ size increased in line with the level of their reproductive investment, but there was no evidence for a reallocation of lipid or protein reserves. The increase in reproductive organ size in high investment mothers was associated with an increase in metabolic rate, but no apparent increase in oxidative damage. Our study suggests that metabolic costs for the mother may play an important role in the maintenance of variation in reproductive investment observed in natural populations.

\section{Methods}

\section{Study population and selection lines}

For this study we used established replicated, divergent Japanese quail selection lines for high and low maternal egg investment (see [24] for a detailed description of the selection procedure). In brief, we selected for high and low relative egg size (i.e. egg size corrected for female body size), by incubating eggs from the highest and lowest $25 \%$ of females from a base population (generation one), creating high investment and low investment lines respectively. In subsequent generations we selected the most extreme $50 \%$ of females within each line. This procedure was repeated twice to create two independent replicates per line (i.e. High 1 / Low 1, High 2 / Low 2). As well as originating from the same base population, high and low investment line birds within a replicate were bred at the same time, meaning that they were all of the same age and experienced the same environmental conditions. By generation four, the lines differed in absolute egg size by 1.2 standard deviations (High investment: $12.46 \pm 0.94 \mathrm{~g}$ (mean $\pm \mathrm{SD})$; Low investment: $11.12 \pm 0.91 \mathrm{~g}$; [24]). The quantity of dry components in the egg (i.e. lipids and protein) responded positively to selection on relative egg size (i.e. larger eggs contained more resources), whilst the rate of egg laying did not change between the two lines as a consequence of selection [24], suggesting that females of the high investment line do not compensate for laying larger eggs by laying fewer or lower quality eggs. Furthermore, this increase in resource investment had a positive effect on the size and early survival of offspring [26].

The birds were kept at the University of Zurich in outdoor aviaries $(5 \times 7.5 \mathrm{~m}$ each). For data collection, females were brought into cages $(122 \times 50 \times 50 \mathrm{~cm})$ within our breeding facility (see below for details about different groups). The bottom of the cages was filled with sawdust, and contained a house, a raised sandbath and ad libitum food, water, grit and shell. Reproduction in quail is strongly influenced by photoperiod [27], so we can manipulate the breeding status of a female by controlling the daylength within our breeding facility. Breeding (i.e. egg-laying) was induced by keeping females on a 16:8 h light:dark cycle, whilst non-breeding birds were kept on a 10:14 h light:dark cycle. At all times our breeding facility was maintained at approximately $20{ }^{\circ} \mathrm{C}$. When entering the cages, body mass (to nearest $1 \mathrm{~g}$ ) and tarsus length (to nearest $0.1 \mathrm{~mm}$ ) were measured. Eggs were collected each morning and weighed to the nearest $0.01 \mathrm{~g}$ (hereafter referred to as egg size).

\section{Body composition}

We dissected breeding females (aged between 38 and 43 weeks) from the fourth generation of the selection lines to investigate differences in body composition between the high $(\mathrm{N}$ : High $1=15$; High $2=20)$ and low $(\mathrm{N}$ : Low $1=16$; Low $2=14)$ investment lines. Females were kept in cages for 4 weeks with a male, and then kept for three to six days in female pairs before dissection (as part of a separate experiment).

The day before dissection, all cages were checked every hour up until one hour before the lights were switched off (21:00) and for every female it was recorded when the egg was laid. The following day females were euthanised, where possible $18 \mathrm{~h}$ after laying to standardise the stage of egg production. Body mass was measured before euthanisation. Oviduct, ovary (including yolky follicles), oviductal egg, liver and pectoral muscles (pectoralis and supracoracoideus) were dissected out and weighed (wet mass to nearest $0.01 \mathrm{~g}$ ). Preliminary data showed that wet and dry masses are highly correlated (oviduct: $r=0.927, \mathrm{~N}=32, P<0.001$; liver: $r=$ 0.890, $\mathrm{N}=32, P<0.001$; pectoral muscle: $r=0.977, \mathrm{~N}=$ $14, P<0.001)$. In the second replicate we also weighed the fat in the body cavity (omentum, $\mathrm{N}=34$ females).

The liver is the site of yolk precursor synthesis [28] and so is expected to change proportionally to egg size. The pectoral muscles and body fat were dissected to test for a potential reallocation of resources from organs involved in flight ability [29] and lipid storage, respectively, to 
reproduction. Although Japanese quail feed and nest on the ground, flight is a vital function in this species, both for their escape response and long-distance migration [30].

To obtain a baseline from which to interpret the differences in organ sizes of breeding individuals between the selection lines (see above), we dissected ten non-breeding females from the unselected base population (aged between 24 and 26 weeks; same founders as selection lines) as described above and compared them to the breeding females from the selection lines. Given the limited number of females from the selection lines, it was not possible to use non-breeding females from the selection lines for this comparison. We expected the differences between high investment and low investment females to mirror (although to a lower magnitude) those between breeding and non-breeding females.

\section{Metabolic rate}

We measured the metabolic rate of females from the fifth generation of the high investment $(\mathrm{N}$ : High $1=7$; High $2=7$ ) and low investment (N: Low $1=7$; Low $2=$ 8) lines. These females were measured twice, once in breeding condition (aged between 14 and 33 weeks) and once, 11 weeks later, in non-breeding condition. Metabolic rate measurements began 5 days after females were put into cages (at which point they were already in breeding or non-breeding condition). These measurements took place over five nights, with six females being measured each night (ensuring that the lines were balanced over the nights). Food was withdrawn from the cages for two to three hours before the measurements started to ensure a post-absorptive state. Females were weighed before being put into respirometry chambers (3.9 I plastic containers; $234 \times 165 \times 165 \mathrm{~mm}$; Lock and Lock, Hanacobi Co. Ltd., Korea) and weighed again in the morning. The chambers were covered by dark material and lights in the windowless room were switched off. The temperature was kept at $24-27{ }^{\circ} \mathrm{C}$, which is within the thermo-neutral zone for this species [31]. We measured the rate of oxygen consumption $\left(\mathrm{VO}_{2}\right)$ using a flow-through respirometry system (Sable Systems International, Las Vegas, USA). Our setup consisted of eight metabolic chambers, six containing quail and two as controls. Air was pumped from the room into each chamber by an eight-channel mass flow meter system (Flowbar-8 Mass Flow Meter/Pump FB-8-1, Sable Systems International, Las Vegas, USA). Air was sampled from one chamber at a time (Multiplexer Intelligent RM-8-2, Sable Systems International, Las Vegas, USA), dried (magnesium perchlorate, Sigma-Aldrich, USA) and analysed (Foxbox, Sable Systems.

International, Las Vegas, USA). The mean flow rate across the nights was $1671 \pm 16 \mathrm{~mL} \mathrm{~min}^{-1}$. We recorded $\mathrm{O}_{2}, \mathrm{CO}_{2}$, flow rate and temperature in consecutive
45 min periods throughout the course of the night. During these $45 \mathrm{~min}$ periods, all eight chambers were measured once for five minutes. One control box was measured twice, once at the beginning and once end of each period, and the other control box was measured once in the middle of each period. As the equipment took a certain time to adjust between chambers, we excluded the first $100 \mathrm{~s}$ of each reading, leaving $200 \mathrm{~s}$ per reading (with 14-18 readings per bird). We regressed all control chamber readings for both $\mathrm{CO}_{2}$ and $\mathrm{O}_{2}$ against time within a $45 \mathrm{~min}$ period, and used this to predict baseline gas levels for chambers containing quail during the same $45 \mathrm{~min}$ period.

These baseline readings were then used to calculate $\mathrm{VO}_{2}$ :

$$
V \mathrm{O}_{2}=\mathrm{FR} \frac{\left(\mathrm{FiO}_{2}-\mathrm{FeO}_{2}\right)-\mathrm{FeO}_{2}\left(\mathrm{FeCO}_{2}-\mathrm{FiCO}_{2}\right)}{1-\mathrm{FeO}_{2}}
$$

[32], where $\mathrm{FiO}_{2}$ and $\mathrm{FiCO}_{2}$ are the baseline $\mathrm{O}_{2}$ and $\mathrm{CO}_{2}$ readings (divided by 100), respectively, $\mathrm{FeO}_{2}$ and $\mathrm{FeCO}_{2}$ are $\mathrm{O}_{2}$ and $\mathrm{CO}_{2}$ readings (divided by 100 ), respectively, for the chamber in question and FR is the flow rate. We define metabolic rate as the lowest, stable $\mathrm{VO}_{2}$ reading of a resting animal, in a post-absorptive state, within its thermalneutral zone. Typically this is described as the basal metabolic rate (BMR), but given that half of our measurements were of females in breeding condition, and so physiologically 'active', we use the broader term resting metabolic rate (RMR; following [33]). RMR therefore represents the basic cost of living. To obtain RMR we calculated the mean $\mathrm{VO}_{2}$ of the lowest, stable one minute during the whole night for each bird.

This measurement of RMR was highly correlated with mean $\mathrm{VO}_{2}$ across the whole night $(r=0.977, \mathrm{~N}=$ $64, P<0.001)$. Repeatability of RMR, based on six birds that were measured twice in non-breeding condition (with 5 days between measurements), was high after correcting for the overall difference between nights $\left(r=0.868 \pm 0.106, F_{5,6}=14.14, P=0.003\right)$.

\section{Oxidative damage}

Three days after the metabolic rate measurements we took a blood sample from all females from the brachial vein using heparinised capillary tubes. Samples were kept on ice until centrifugation $\left(5 \mathrm{~min}\right.$ at $20{ }^{\circ} \mathrm{C}$ and $2000 \times \mathrm{g}$ ). Plasma was then separated and frozen at $-80{ }^{\circ} \mathrm{C}$ until analysis. As a measure of oxidative damage we quantified the plasma concentration of reactive oxygen metabolites (ROMs) using the dROMs test (Diacron International, Grosseto, Italy). This is a colorimetric assay, which measures intermediate oxidative damage molecules (mainly hydroperoxides; [34]) that are produced by the peroxidation of a diverse range of biomolecules [35]. Our 
analysis followed previously published protocols [36, 37]. In short $8 \mu \mathrm{l}$ plasma was diluted with $200 \mu \mathrm{l}$ of a solution containing acetate buffer ( $\mathrm{pH} 4.8)$ and an aromatic alkylamine (chromogen). The samples were incubated at $37^{\circ} \mathrm{C}$ for $75 \mathrm{~min}$, centrifuged and the supernatant was pipetted onto a microplate. The absorbance was then read with a spectrometer (Multiskan Spectrum, ThermoFisher, Vantaa, Finland) at a wavelength of $505 \mathrm{~nm}$. All samples were run in duplicate. Results were calculated as $\mathrm{mM}$ of $\mathrm{H}_{2} \mathrm{O}_{2}$ equivalents. There was a high repeatability of ROMs measures within samples $\left(r=0.993 \pm 0.002, F_{55,56}=282.61, P<0.001\right)$. The inter-assay coefficient of variation was $8.12 \%$, and the intra-assay coefficient of variation was $1.55 \%$. In order to correct for plate differences in ROMs, we centered all samples from a plate on the control samples for that plate. One low line female had blood taken only once, and so was excluded from the oxidative damage analyses.

\section{Statistical analysis}

We compared differences in total body mass (at time of dissection), reproductive organ mass, non-reproductive mass, liver, fat and pectoral muscle mass, as well as metabolic rate and oxidative damage between the selection lines and between non-breeding and breeding individuals. Reproductive organ mass included oviduct mass, ovary mass and the mass of yolky follicles. Non-reproductive mass was calculated as the total body mass minus reproductive organ mass and oviductal egg mass. All measures were log transformed prior to analysis to account for scaling effects on variance.

To test for differences in body composition between non-breeding and breeding females, we used two sample t-tests and a Welch/Satterthwaite approximation for the degrees of freedom due to unequal sample sizes and variances. One non-breeding female was excluded from the analysis, as during dissection it was clear from the state of her ovary and oviduct that she had started to come into breeding condition.

To test for differences in body composition between breeding females from the high and low investment lines, we used linear models, including selection line and replicate as factors. Tarsus length (cubed prior to log transformation) was included as a covariate to account for body size differences among females. For the analysis of total body mass and reproductive organ mass, we included only the 55 females that were dissected approximately $18 \mathrm{~h}$ after laying, as the mass of the reproductive organs varies with the stage of egg development $(\mathrm{N}$ : High $1=12$; High 2 = 19; Low 1 = 13; Low 2 = 11).

Body mass (i.e. mass when entering the metabolic chamber), metabolic rate and oxidative damage of the females measured in generation five, were measured twice, once in breeding and once in non-breeding condition. To test whether the change in these traits between non-breeding and breeding condition was different between the lines, we ran linear mixed models with selection line, breeding status and replicate as factors as well as the interaction between selection line and breeding status. Age and tarsus length were included as covariates and again tarsus length was cubed prior to log transformation. Female ID was included as a random effect. In the metabolic rate models, we also included measurement date as a random effect to account for stochastic differences in RMR measurements between nights.

If the level of reproductive investment affects the increase in body mass, metabolic rate and/or oxidative damage, we predict to see a significant interaction effect between line and breeding status in all of these models. If the increase in metabolic rate is driven by an increase in body mass, then we predict to find this interaction when correcting for body size (tarsus length) but not when correcting for body mass. Similarly, if the increase in oxidative damage is driven by an increase in metabolic rate, we predict to no longer find an interaction effect between breeding status and line when correcting for metabolic rate or body mass. To test these hypotheses we ran an additional model for metabolic rate with $\log$ transformed body mass as a covariate instead of tarsus length and two additional models for oxidative damage including log transformed body mass and log transformed metabolic rate, respectively. In these models the added covariate was always retained in the model.

Additionally we used paired t-tests to test whether body mass, metabolic rate and oxidative damage differed between individuals in breeding and non-breeding condition.

We included these tests to demonstrate the magnitude and direction of the difference between breeding and non-breeding birds, and to allow a comparison with the body composition data. Finally we tested whether the within individual change between non-breeding and breeding condition in all three measures correlated with each other, as well as with mean egg size and tarsus length.

All analyses were run in R (3.0.3, [38]). In all models, we performed backward stepwise deletion of nonsignificant terms. Significance was determined using F statistics in linear models and likelihood ratio tests with one degree of freedom in mixed effects models. We present means \pm SD.

\section{Results \\ Body composition}

Breeding females (from both selection lines) were significantly heavier than non-breeding females (non-selected birds; Table 1). This mass difference between breeding and non-breeding females ( $30 \mathrm{~g})$ was mainly due to an increase in reproductive organ mass $(15.18 \pm 1.73)$ plus oviductal egg mass $(11.72 \pm 1.14$; total $=26.36 \pm 3.88 \mathrm{~g})$. 
Table 1 Body composition, metabolic rate (RMR) and oxidative damage (ROMs) of breeding and non-breeding females

\begin{tabular}{|c|c|c|c|c|c|}
\hline Trait & Breeding & Non Breeding & $t$ & df & $P$ \\
\hline \multicolumn{6}{|l|}{ Generation 4} \\
\hline \multicolumn{6}{|l|}{ Body Mass } \\
\hline Total Body Mass (g) & $288 \pm 35$ & $258 \pm 28$ & 2.84 & 10.90 & 0.016 \\
\hline Non-Repro. Mass (g) & $262 \pm 33$ & $258 \pm 28$ & 0.36 & 11.07 & 0.724 \\
\hline \multicolumn{6}{|l|}{ Body Size } \\
\hline Tarsus Length (mm) & $40.0 \pm 1.4$ & $39.8 \pm 1.1$ & 0.38 & 12.09 & 0.712 \\
\hline \multicolumn{6}{|c|}{ Reproductive and Associated Organs } \\
\hline Repro. Organs (g) & $15.18 \pm 1.73$ & $0.31 \pm 0.12$ & 39.30 & 8.36 & $<0.001$ \\
\hline Liver (g) & $7.98 \pm 1.06$ & $4.66 \pm 0.80$ & 9.78 & 9.60 & $<0.001$ \\
\hline \multicolumn{6}{|l|}{ Protein and Lipid Reserves } \\
\hline Pectoral Muscles (g) & $51.85 \pm 7.53$ & $51.38 \pm 4.67$ & 0.08 & 14.43 & 0.939 \\
\hline Body Fat (g) & $4.96 \pm 3.00$ & $8.59 \pm 3.94$ & -3.29 & 21.45 & 0.003 \\
\hline \multicolumn{6}{|l|}{ Generation 5} \\
\hline Body Mass $(g)^{1}$ & $254 \pm 20$ & $240 \pm 17$ & 4.20 & 28 & $<0.001$ \\
\hline $\operatorname{RMR}\left(\mathrm{mL} \mathrm{O} \mathrm{min}^{-1}\right)$ & $6.01 \pm 0.67$ & $3.52 \pm 0.37$ & 22.73 & 28 & $<0.001$ \\
\hline $\mathrm{ROMs}\left(\mathrm{mM} \mathrm{H}_{2} \mathrm{O}_{2}\right)$ & $0.882 \pm 0.263$ & $0.801 \pm 0.228$ & 1.22 & 27 & 0.232 \\
\hline
\end{tabular}

Means \pm SD are shown. In generation 4, females were measured once, either in breeding $(N=65)$ or in non-breeding $(N=10)$ condition. In generation 5 , females $(N=29)$ were measured twice, once in breeding and once in non-breeding condition. Repro. is abbreviation for Reproductive. Significant results are displayed in bold ${ }^{1}$ The difference in body mass between the two states is less than in generation 4 due to measuring the birds at different times of day (here the majority of females had already laid an egg)

Non-reproductive mass did not differ between non-breeding and breeding females (Table 1). Breeding females also had heavier livers and less body fat than nonbreeding females, but there was no difference in pectoral muscle mass (Table 1).

Similarly, high investment females tended to be heavier than low investment females when correcting for body size (generation 4; Table 2). Furthermore, the change in body mass between breeding and non-breeding condition was significantly larger in high investment females $(22 \pm 14 \mathrm{~g})$ than low investment females $(7 \pm 19 \mathrm{~g}$; generation 5 ; Table 3, Fig. 1a).
After correcting for body size, the reproductive organs were significantly heavier in high investment females than in low investment females, whereas non-reproductive mass did not differ between the lines (Table 2). Moreover, egg size was highly correlated with reproductive organ mass $(r=0.810, \mathrm{~N}=54, P<0.001)$. No differences in fat, liver or pectoral muscle mass were observed between the lines after correcting for body size (Table 2).

\section{Metabolic rate and oxidative damage}

Females increased their resting metabolic rate by $70 \%$ when entering breeding condition (Table 1). This change

Table 2 Difference in body composition of breeding females between selection lines, correcting for replicate and body size

\begin{tabular}{|c|c|c|c|c|c|c|c|c|c|}
\hline \multirow[t]{2}{*}{ Trait } & \multicolumn{3}{|l|}{ Line } & \multicolumn{3}{|c|}{ Replicate } & \multicolumn{3}{|c|}{ Tarsus Length } \\
\hline & $F$ & $\mathrm{df}$ & $P$ & $F$ & $\mathrm{df}$ & $P$ & $F$ & df & $P$ \\
\hline \multicolumn{10}{|l|}{ Body Mass } \\
\hline Total Body Mass & 3.33 & 52 & 0.074 & 0.51 & 51 & 0.480 & 40.89 & 53 & $<0.001$ \\
\hline Non-Repro. Mass & 1.92 & 62 & 0.171 & 0.34 & 61 & 0.561 & 39.19 & 63 & $<0.001$ \\
\hline \multicolumn{10}{|c|}{ Reproductive and Associated Organs } \\
\hline Repro. Organs & 7.15 & 51 & 0.010 & 9.32 & 51 & 0.004 & 19.73 & 51 & $<0.001$ \\
\hline Liver & 0.94 & 62 & 0.336 & 0.02 & 61 & 0.891 & 3.99 & 63 & 0.050 \\
\hline \multicolumn{10}{|c|}{ Protein and Lipid Reserves } \\
\hline Pectoral Muscles & 1.65 & 61 & 0.204 & 19.19 & 62 & $<0.001$ & 37.09 & 62 & $<0.001$ \\
\hline Body Fat & 0.00 & 32 & 0.958 & - & - & - & 0.00 & 31 & 0.994 \\
\hline
\end{tabular}


Table 3 Difference between the selection lines in body mass (BM), metabolic rate (RMR) and oxidative damage (ROMs) according to breeding status

\begin{tabular}{|c|c|c|c|c|c|c|c|c|c|c|c|c|c|c|c|c|c|}
\hline \multirow[t]{2}{*}{ Trait } & \multirow[t]{2}{*}{ Model } & \multicolumn{2}{|l|}{ Line } & \multicolumn{2}{|l|}{ Status } & \multicolumn{2}{|c|}{ Line $\times$ Status } & \multicolumn{2}{|c|}{ Replicate } & \multicolumn{2}{|l|}{ Age } & \multicolumn{2}{|c|}{ Tarsus Length } & \multicolumn{2}{|c|}{ Body Mass } & \multicolumn{2}{|l|}{ RMR } \\
\hline & & $x^{2}$ & $P$ & $x^{2}$ & $P$ & $x^{2}$ & $P$ & $x^{2}$ & $P$ & $x^{2}$ & $P$ & $x^{2}$ & $P$ & $x^{2}$ & $P$ & $x^{2}$ & $P$ \\
\hline $\mathrm{BM}$ & a & - & - & - & - & 5.29 & 0.021 & 0.19 & 0.665 & 0.88 & 0.347 & 10.73 & 0.001 & - & - & - & - \\
\hline \multirow[t]{2}{*}{ RMR } & a & - & - & - & - & 4.82 & 0.028 & 0.21 & 0.646 & 0.00 & 0.947 & 2.17 & 0.141 & - & - & - & - \\
\hline & $b$ & 0.16 & 0.688 & 30.57 & $<0.001$ & 1.10 & 0.294 & 0.12 & 0.734 & 0.45 & 0.503 & - & - & 30.01 & $<0.001$ & - & - \\
\hline \multirow[t]{3}{*}{ ROMs } & a & 0.06 & 0.802 & 1.85 & 0.174 & 3.08 & 0.079 & 3.08 & 0.079 & 2.00 & 0.158 & 1.07 & 0.300 & - & - & - & - \\
\hline & $b$ & 0.28 & 0.596 & 1.87 & 0.172 & 3.20 & 0.074 & 3.44 & 0.064 & 1.69 & 0.193 & - & - & 0.02 & 0.880 & - & - \\
\hline & c & 0.55 & 0.459 & 0.27 & 0.607 & 3.19 & 0.074 & 3.67 & 0.056 & 1.68 & 0.195 & - & - & - & - & 1.14 & 0.287 \\
\hline
\end{tabular}

Significant results are displayed in bold. For metabolic rate and oxidative damage, several models were run, including a) tarsus length, b) body mass and c) metabolic rate as covariates. In all models $\mathrm{df}=1$

in RMR was significantly larger in high investment females $\left(2.79 \pm 0.65 \mathrm{~mL} \mathrm{O}_{2} \mathrm{~min}^{-1}\right)$ than low investment females $\left(2.21 \pm 0.54 \mathrm{~mL} \mathrm{O}_{2} \mathrm{~min}^{-1}\right.$; Table 3, Fig. 1b). When correcting for body mass instead of body size, the change in RMR did not differ between the lines, but there was still a significant difference in RMR between breeding and non-breeding individuals (Table 3). This demonstrates that the differential increase in RMR between the lines was mediated by the greater increase in body mass between non-breeding and breeding states in high investment line females.

Overall, there was no difference in oxidative damage when an individual was in breeding or non-breeding condition (Table 1). There was a trend for an interaction between line and breeding status on oxidative damage (Table 3; Fig. 1c), but in the opposite direction than predicted: the oxidative damage of low investment females tended to increase with breeding (paired $t$ test: $t_{13}=1.96$, $P=0.072$ ) whilst there was no change in oxidative damage between non-breeding and breeding condition in high investment females (paired $t$ test: $t_{13}=0.24, P=0.815$ ).
When correcting for either body mass or RMR instead of body size, there was no qualitative change in the results (Table 3).

The changes in both body mass and RMR between non-breeding and breeding were highly correlated with each other, and both were correlated with egg size, but not with tarsus length (Table 4). Change in oxidative damage was not correlated with any other variable. Egg size and tarsus length were not correlated (Table 4).

\section{Discussion}

Female body mass increased when entering breeding condition. This increase was larger in females from the high investment lines than the low investment lines and was mainly driven by an increase in reproductive organ mass. Whereas an increase in body mass when entering reproductive condition has been documented in other species [39-41], this is the first experimental evidence that the magnitude of body mass change relates to the level of maternal reproductive investment.
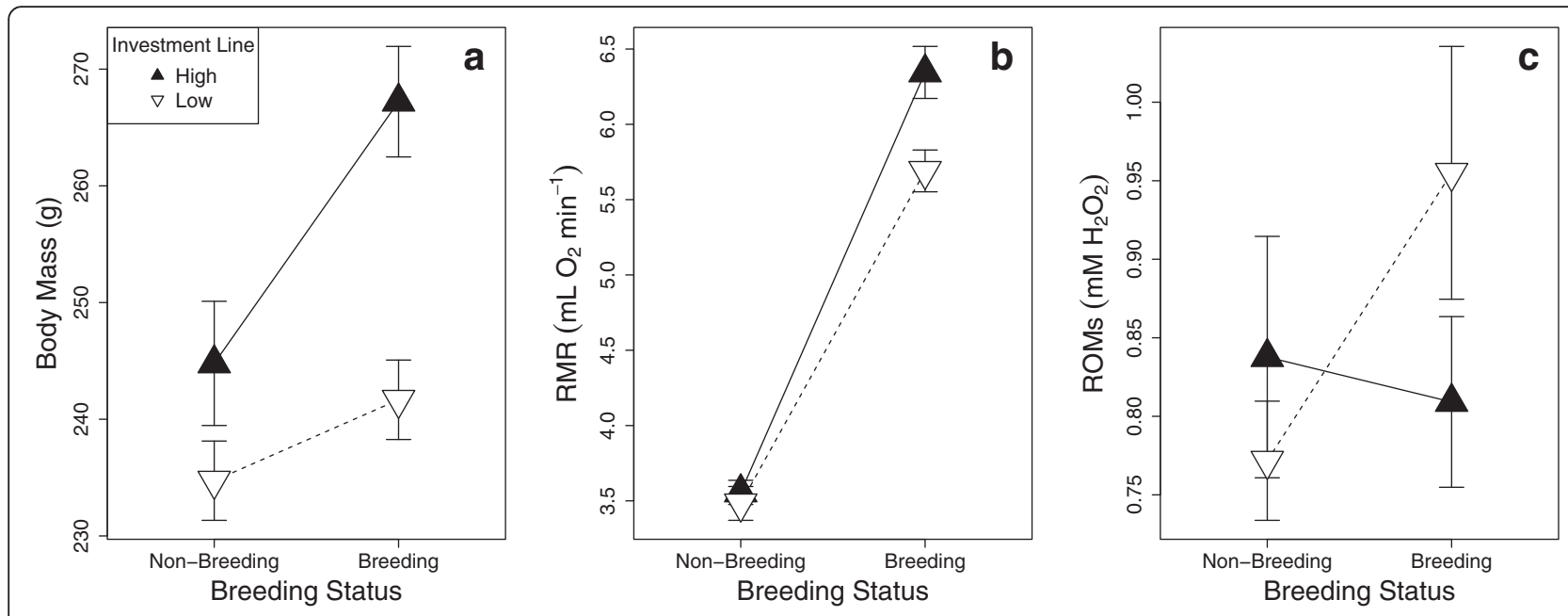

Fig. 1 The effect of selection line and breeding status on a) body mass, b) metabolic rate (RMR) and c) oxidative damage (ROMs) 
Table 4 Correlations between individual differences in body mass, metabolic rate (RMR) and oxidative damage (ROMs) between breeding and non-breeding condition, egg size and tarsus length

\begin{tabular}{llllll}
\hline & $\Delta$ Body Mass & $\Delta$ RMR & $\Delta$ ROMs & Egg Size & Tarsus Length \\
\hline$\triangle$ Body Mass & - & $\mathbf{0 . 0 0 3}$ & 0.822 & $\mathbf{0 . 0 0 0}$ & 0.309 \\
$\Delta$ RMR & 0.539 & - & 0.439 & $\mathbf{0 . 0 1 2}$ & 0.292 \\
$\Delta$ ROMs & 0.045 & -0.152 & - & 0.436 & 0.558 \\
Egg Size & 0.726 & 0.483 & -0.153 & - & 0.082 \\
Tarsus Length & 0.213 & 0.205 & -0.116 & 0.318 & -
\end{tabular}

Below the diagonal Pearson correlation coefficients are displayed, above the diagonal the $P$ value. Significant results are displayed in bold

Previous work has shown that in many taxa predator escape responses are negatively affected by body mass and the additional weight of carrying eggs [42-45]. Furthermore, within-female decreases in flight performance between non-breeding and breeding has been shown to be correlated with the corresponding increase in body mass [45]. As high investment females increase their body mass to a larger degree than low investment females, their predator escape response is likely more strongly compromised, given that small increases in mass have large impacts on the time taken to reach cover [46].

High investment line females also displayed a greater increase in RMR between non-breeding and breeding condition than low investment line females. This differential change in RMR was driven by body mass, but not body size, and so by the change in reproductive organ mass. Although it is generally observed that females increase both daily energy expenditure (DEE) and RMR when entering breeding condition (e.g. [47]), there is only inconsistent correlative evidence of a link between the level of maternal egg investment and DEE [48-51] or RMR [33, 47, 52]. Our study thus provides the first experimental evidence that the level of maternal egg investment leads to a proportional increase in metabolic rate. This energetic cost of increased maternal investment is likely to be severe, as egg production occurs at a time of relatively low food abundance [12, 39]. Additionally, previous studies have found that both RMR and DEE are associated with food intake and activity [12, 39, 53, 54] and that changes in RMR are compensated by changes in food intake [55]. Therefore birds with higher energetic demands will have to spend more time searching for food, which will increase their predation risk $[16,17,56]$.

Surprisingly, despite an increase in RMR, we did not find a corresponding increase in oxidative damage, either between non-breeding and breeding condition or between the selection lines. If anything, there was a tendency for low investment line females to suffer a more marked increase in oxidative damage between non-breeding and breeding than high investment line females. Although oxidative stress has been proposed to be a key mediator of life-history trade-offs $[14,15]$, the empirical evidence for a link between reproduction and oxidative stress is equivocal [57]. Furthermore, the idea has been criticised on the basis that ROS may not be produced in direct relation to metabolic rate, with some studies even showing that high metabolic rates can lead to a proportionally lower production of ROS (reviewed in [57]). A recent meta-analysis showed that the levels of oxidative stress do not change, or if anything tend to decrease, between non-breeding and breeding individuals [58]. Furthermore, although the authors also found that oxidative damage tends to increase with reproductive effort [58], this finding is driven by mammalian studies and there is, in line with our results, no compelling evidence of this phenomenon in birds [59-61]. Moreover, high levels of oxidative stress due to increased reproductive effort should come at the cost of reduced future survival, of which there is little evidence [62]. Together, these findings raise questions about the role of oxidative stress in mediating life-history trade-offs in birds.

It is important to note, that although we use a very common measure of oxidative damage (i.e. dROMS in blood plasma [37]), our results may have been different if we measured a different biomarker or tissue [57]. Furthermore, the effects of higher RMR on oxidative status could have been masked by ad libitum food conditions, although it is not clear that food availability mediates such a link (see discussion in [57]).

The change in RMR between non-breeding and breeding was not completely explained by the increase in body mass. This additional increase in RMR might be explained by a change in body composition. Indeed, between non-breeding and breeding condition, the size of the liver, which is metabolically highly active, increased whilst body fat decreased (see also [63, 64]). The liver is the site of yolk precursor synthesis, which is the only part of egg synthesis that requires lipids [65]. Therefore, these changes in fat and liver size may reflect the general mobilisation of lipids from storage to the liver for yolk precursor synthesis and the associated biosynthetic activity [64]. However, there was no evidence that these changes differed between the selection lines. This is in agreement with previous studies that found that the amount of yolk precursors in the plasma of breeding females was not positively correlated to yolk size or composition [12, 66, 67]. Moreover, hormonally increased yolk precursor levels caused no change in egg size $[68,69]$ and selection on yolk precursor levels affected liver size, but not egg size or production [70]. This has lead to the suggestion that females overproduce lipid-rich yolk precursors [12]. Our results corroborate this hypothesis, showing that changes in liver size and fat storage are related to reproduction per se, rather than 
the level of reproductive investment (see also [63]), which may explain why lipid supplementation has little effect on egg size [64]. Thus, there is no indication for a trade-off between reproductive investment and fat reserves, or that the liver contributes to the increased metabolic rate of high investment line females. This contrasts with other taxa in which fat is a major energetic currency in the trade-off between reproduction and somatic maintenance [71].

Traditionally body mass relative to body size has been used as a measure of body condition, which is thought to represent levels of lipid reserves [72] and is usually interpreted as an environmentally determined quality trait [73]. Several studies have shown that egg size correlates with body condition (reviewed in [20]) and concluded that female nutrient reserves influence variation in egg size (e.g. [74-76]). However, our results suggest that laying larger eggs requires larger reproductive organs, which results in an increase in body mass and so the appearance of better 'body condition'. This measure of body condition has recently been criticised [72], and our finding that females investing differently in their eggs display a difference in body mass but no difference in body fat, further shows that this measure is inappropriate in breeding females, as it may lead to the false conclusion that residual fat reserves influence reproductive output.

Pectoral muscles are often used as a source of protein during egg production [12]. Several studies have shown that females reduce the size of their pectoral muscles when they are experimentally forced to lay more eggs ([77-79]; but see [63]), in line with the idea that the availability of proteins, rather than lipids, limit egg production [64]. This reallocation of resource can have negative effects on flight ability [78], and so the ability to raise offspring [77] and evade predators (but see [80]). Despite these previous findings, we found no difference in pectoral muscle mass either between non-breeding and breeding females or between the selection lines. It is possible that there are more subtle changes in pectoral muscle composition or structure that we could not detect.

However, our measure of muscle mass is highly correlated with dry muscle mass. Moreover, all previous experimental studies that found a decrease in muscle mass with increased egg laying [77-79], muscles condition was assessed non-destructively through the use of external measurements $[81,82]$, which correlates strongly with the method we used [83]. Furthermore, our method has been used to demonstrate a decrease in muscle mass between non-breeding and breeding condition [84], showing that the method is sensitive enough to detect a reallocation, if one was present. One explanation for the lack of a reallocation of resources from muscle tissue to reproduction could be that, in our study, birds had access to ad libitum food and so protein may not have been limiting. However, previous studies have found this reallocation under similar conditions [78, 84, 85], showing that trade-offs between reproduction and muscle maintenance can also be detected in captivity. We did not measure leg muscle mass, which is likely important for locomotory function in ground living birds such as quail.

However, it seems unlikely that a protein reallocation would be confined to the leg muscle, especially given that the pectoral muscle is much larger. Overall, our results therefore suggest that protein reallocation is not an obligate response to reproduction or the level of reproductive investment.

Several authors have suggested that the cost of increased reproductive investment may be passed to the offspring, rather than being dealt with by the mother $[62,86]$. For example, a recent study showed that food supplemented females experience lower oxidative damage, but do not provision their eggs with more antioxidants [87], suggesting a prioritisation of selfmaintenance. Similar results have been found in other taxa (e.g. [61, 88, 89]), and may explain why, across studies, females do not appear to suffer survival costs as a consequence of experimentally increased reproductive investment [62]. Furthermore, females may experience a trade-off between reproduction and functions that we have not measured in our study, such as immune function [90] or brain size [91]. Testing for such additional costs, as well as for differences in egg constituents [87] and the oxidative stress of offspring [92] between the lines will thus give greater resolution to our understanding of the costs of per offspring investment.

\section{Conclusions}

Our study provides experimental evidence that increased female egg investment is associated with an increase in reproductive organ mass, leading to an increase in both body mass and metabolic rate during breeding. Surprisingly, the increased metabolic rate of high investment females did not result in higher levels of oxidative damage.

Both increased body mass and increased metabolic rate are likely to increase predation risk, through increasing food requirement whilst reducing escape ability. This study thus provides the first experimental evidence for metabolic costs of increased per offspring resource allocation, which are likely to be a key driver in the maintenance of variation in maternal reproductive investment.

\section{Acknowledgements}

We thank Alison Pick and Barbara Schnüriger for help with animal husbandry, Jennifer Morger, Cindy Canale, Silvan Pfändler and Sabine Frei for help with data collection and Mathieu Giraudeau and Mélissa Lemoine for discussions. The study was financially supported by the Swiss National Science Foundation (PPOOP3 128386 and 458 PPOOP3 157455 to BT). 


\section{Availability of data and materials}

The data that support the findings of this study are available from the corresponding author upon reasonable request.

\section{Authors' contributions}

Study was conceived by JLP and BT. Selection lines were established by JLP, dissections were conducted by JLP, PH and CE, respirometry by $A Z$ and JLP, and oxidative stress assays by MG. Data were analysed by JLP and results interpreted by JLP and BT. Manuscript was drafted by JLP and revised by all authors. All authors read and approved the final manuscript.

\section{Competing interests}

The authors declare that they have no competing interests.

\section{Ethics approval and consent to participate}

All procedures were conducted under licenses provided by the Veterinary Office of the Canton of Zurich, Switzerland (permit numbers 195/2010; 14/2014; 156).

\section{Received: 18 March 2016 Accepted: 18 August 2016}

\section{Published online: 23 August 2016}

\section{References}

1. Henry CJK, Ulijaszek SJ. Long-term Consequences of Early Environment. Cambridge: Cambridge University Press; 1996.

2. Lindström J. Early development and fitness in birds and mammals. Trends in Ecology and Evolution. 1999;14:34-348.

3. Mousseau T, Fox CW. Maternal effects as adaptations. Oxford: Oxford University Press; 1998.

4. Maestripieri D, Mateo JM. Maternal effects in mammals. Chicago: University of Chicago Press; 2009

5. Houle D. Comparing evolvability and variability of quantitative traits. Genetics. 1992:130:195-204.

6. Postma E. Four decades of estimating heritabilities in wild vertebrate populations: improved methods, more data, better estimates? In: Charmantier A, Garant D, Kruuk LEB, editors. Quantitative Genetics in the Wild. Oxford: Oxford University Press; 2014. p. 16-33.

7. Williams GC. Natural selection, the costs of reproduction, and a refinement of Lack's principle. Am Nat. 1966;100:687-90.

8. Roff DA. The Evolution of Life Histories: Theory and Analysis. New York: Chapman \& Hall; 1992

9. Stearns SC. The Evolution of Life Histories. Oxford: Oxford University Press; 1992

10. Zera AJ, Harshman LG. The physiology of life history trade-offs in animals. Annu Rev Ecol Syst. 2001;32:95-126.

11. Harshman LG, Zera AJ. The cost of reproduction: the devil in the details. Trends in Ecology and Evolution. 2006;22:80-6.

12. Williams TD. Mechanisms underlying the costs of egg production. Bioscience. 2005:55:39-48.

13. Koopman WJH, Nijtmans LGJ, Dieteren CEJ, Roestenberg P, Valsecchi F, Smeitink JAM, Willems PHGM. Mammalian mitochondrial complex I: biogenesis, regulation, and reactive oxygen species generation. Antioxidants and Redox Signalling. 2010;12:1431-70.

14. Monaghan P, Metcalfe NB, Torres R. Oxidative stress as a mediator of life history trade-offs: mechanisms, measurements and interpretation. Ecol Lett. 2009;12:75-92

15. Metcalfe NB, Monaghan P. Does reproduction cause oxidative stress? An open question Trends in Ecology and Evolution. 2013;28:347-50.

16. Hilton GM, Ruxton GD, Cresswell W. Choice of foraging area with respect to predation risk in redshanks: the effects of weather and predator activity. Oikos. 1999;87:295-302.

17. Martin TE, Scott J, Menge C. Nest predation increases with parental activity: separating nest site and parental activity effects. Proc R Soc Lond B. 2000; 267:2287-93.

18. van Noordwijk AJ, de Jong G. Acquisition and allocation of resources: their influence on variation in life history tactics. Am Nat. 1986;128:137-42.

19. Williams TD. Intraspecific variation in egg size and egg composition in birds: effects on offspring fitness. Biol Rev Camb Philos Soc. 1994;69:35-59.

20. Christians JK. Avian egg size: variation within species and inflexibility within individuals. Biol Rev Camb Philos Soc. 2002;77:1-26.

21. Monaghan P, Nager RGG. Why don't birds lay more eggs? Trends in Ecology and Evolution. 1997;12:270-4.
22. Czesak ME, Fox CW. Evolutionary ecology of egg size and number in a seed beetle: genetic trade-off differs between environments. Evolution. 2003:57:1121-32.

23. Fischer K, Bot ANM, Brakefield PM, Zwaan BJ. Do mothers producing large offspring have to sacrifice fecundity? J Evol Biol. 2006;19:380-91.

24. Pick JL, Hutter $P$, Tschirren B. In search of genetic constraints limiting the evolution of egg size: direct and correlated responses to artificial selection on a prenatal maternal effector. Heredity. 2016;116:542-9.

25. Schwarzkopf L, Blows M, Caley M. Life-history consequences of divergent selection on egg size in Drosophila melanogaster. Am Nat. 1999;154:333-40.

26. Pick JL, Ebneter C, Hutter P, Tschirren B. Disentangling genetic and prenatal maternal effects on offspring size and survival. Am Nat. 2016. In Press.

27. Adkins EK. Functional castration of the female Japanese quail. Physiol Behav. 1973;10:619-21.

28. Williams TD, Reed WL, Walzem RL. Egg size variation: Mechanisms and hormonal control. In: Dawson A, Chaturvedi CM, editors. Avian Endocrinology. New Delhi: Narosa Publishing House; 2001. p. 205-17.

29. Veasey JS, Houston DC, Metcalfe NB. Flight muscle atrophy and predation risk in breeding birds. Funct Ecol. 2000;14:115-21.

30. Johnsgard PA. The Quails, Partridges, and Francolins of the World. Oxford: Oxford University Press; 1988

31. Ben-Hamo M, Pinshow B, McCue MD, McWilliams SR, Bauchinger U. Fasting triggers hypothermia, and ambient temperature modulates its depth in Japanese quail Coturnix japonica. Comparative Biochemistry and Physiology A. 2010;156:84-91.

32. Lighton JRB. Measuring Metabolic Rates: A Manual For Scientists. Oxford: Oxford University Press; 2008.

33. Vézina F, Williams TD. Metabolic costs of egg production in the european starling (Sturnus vulgaris). Physiol Biochem Zool. 2002;75:377-85.

34. Alberti A, Bolognini L, Macciantelli D, Caratelli M. The radical cation of $\mathrm{N}$, $\mathrm{N}$-diethyl-para-paraphenylendiamine: a possible indicator of oxidative stress in biological samples. Res Chem Intermed. 2000;26:253-67.

35. Halliwell B, Gutteridge G. Free Radicals in Biology and Medicine. 4th ed. Oxford: Oxford University Press; 2007.

36. Costantini D, Monaghan P, Metcalfe NB. Biochemical integration of blood redox state in captive zebra finches (Taeniopygia guttata). J Exp Biol. 2011;214:1148-52.

37. Costantini D. Oxidative stress ecology and the d-ROMs test: facts, misfacts and an appraisal of a decade's work. Behav Ecol Sociobiol. 2016;70:809-20.

38. R Core Team: R: A Language and Environment for Statistical Computing. $R$ Foundation for Statistical Computing, Vienna (2014). R Foundation for Statistical Computing. http://www.r-project.org/.

39. Perrins C. Eggs, egg formation and the timing of breeding. Ibis. 1996;138:2-15.

40. Woodburn R, Perrins C. Weight change and the body reserves of female blue tits, Parus caeruleus, during the breeding season. J Zool. 1997;243:789-802.

41. Ward S, Bryant DM. Barn swallows Hirundo rustica form eggs mainly from current food intake. J Avian Biol. 2006:37:179-89.

42. Van Damme R, Bauwens D, Veheyen RF. Effect of relative clutch mass on sprint speed in the lizard Lacerta vivipara. J Herpetol. 1989;23:459-4619.

43. Cooper WE, Vitt LJ, Hedges R, Huey RB. Locomotor impairment and defense in gravid lizards (Eumeces laticeps): behavioral shift in activity may offset costs of reproduction in an active forager. Behav Ecol Sociobiol. 1990;27:153-7.

44. Witter MS, Cuthill IC, Bonser RHC. Experimental investigations of massdependent predation risk in the European starling, Sturnus vulgaris. Anim Behav. 1994:48:201-22.

45. Lee SJ, Witter MS, Cuthill IC, Goldsmith AR. Reduction in escape performance as a cost of reproduction in gravid starlings, Sturnus vulgaris. Proc R Soc Lond B. 1996;263:619-23.

46. Bednekoff PA. Translating mass dependent flight performance into predation risk: an extension of Metcalfe \& Ure. Proc R Soc Lond B. 1996;263:887-9.

47. Nilsson J $\AA$, Råberg $L$. The resting metabolic cost of egg laying and nestling feeding in great tits. Oecologia. 2001;128:187-92.

48. Ward S, MacLeod MG. Energy cost of egg formation in quail. Proc Nutr Soc. 1992;51:41.

49. Ward S. Expenditure energy of female barn swallows Hirundo rustica during egg formation. Physiol Zool. 1996;69:930-51.

50. Stevenson IR, Bryant DM. Climate change and constraints on breeding. Nature. 2000:406:366-7.

51. te Marvelde L, Webber SL, Meijer HAJ, Visser ME. Energy expenditure during egg laying is equal for early and late breeding free-living female great tits. Oecologia. 2012;168:631-8. 
52. Vézina F, Williams TD. The metabolic cost of egg production is repeatable. J Exp Biol. 2005;208:2533-8.

53. Selman C, Lumsden S, Bünger L, Hill WG, Speakman JR. Resting metabolic rate and morphology in mice (Mus musculus) selected for high and low food intake. J Exp Biol. 2001;204:777-84.

54. Vézina F, Speakman JR, Williams TD. Individually variable energy management strategies in relation to energetic costs of egg production. Ecology. 2006;87:2447-58.

55. Johnston SL, Souter DM, Tolkamp BJ, Gordon IJ, Illius AW, Kyriazakis I, Speakman JR. Intake compensates for resting metabolic rate variation in female C57BL/6 J mice fed high-fat diets. Obesity. 2007;15:600-6.

56. Magnhagen C. Predation risk as a cost of reproduction. Trends in Ecology and Evolution. 1991;6:183-6.

57. Speakman JR, Garratt M. Oxidative stress as a cost of reproduction: beyond the simplistic trade-off model. BioEssays. 2014;36:93-106.

58. Blount JD, Vitikainen EIK, Stott I, Cant MA. Oxidative shielding and the cost of reproduction. Biol Rev. 2016;91:483-97.

59. Costantini D, Bonisoli-Alquati A, Rubolini D, Caprioli M, Ambrosini R, Romano M, Saino N. Nestling rearing is antioxidant demanding in female barn swallows (Hirundo rustica). Naturwissenschaften. 2014;101:541-8.

60. Wegmann M, Voegeli B, Richner H. Oxidative status and reproductive effort of great tits in a handicapping experiment. Behav Ecol. 2015;26:747-54.

61. Wegmann M, Voegeli B, Richner H. Physiological responses to increased brood size and ectoparasite infestation: adult great tits favour selfmaintenance. Physiol Behav. 2015;141:127-34.

62. Santos ESA, Nakagawa S. The costs of parental care: a meta-analysis of the trade-off between parental effort and survival in birds. J Evol Biol. 2012;25:1-7.

63. Christians JK. Producing extra eggs does not deplete macronutrient reserves in european starlings Sturnus vulgaris. J Avian Biol. 2000;31:312.

64. Nager RG. The challenges of making eggs. Ardea. 2006;94:323-46.

65. Romanoff A, Romanoff A. The Avian Egg. New York: Wiley; 1949.

66. Challenger WO, Williams TD, Christians JK, Vézina F. Follicular development and plasma yolk precursor dynamics through the laying cycle in the european starling (Sturnus vulgaris). Physiol Biochem Zool. 2001;74:356-65

67. Christians JK, Williams TD. Intraspecific variation in reproductive physiology and egg quality in the european starling (Sturnus vulgaris). J Avian Biol. 2001;74:356-65.

68. Christians JK, Williams TD. Effects of exogenous 17beta-estradiol on the reproductive physiology and reproductive performance of european starlings (Sturnus vulgaris). J Exp Biol. 1999;202:2679-85.

69. Williams TD. Parental and first generation effects of exogenous 17 betaestradiol on reproductive performance of female zebra finches (Taeniopygia guttata). Horm Behav. 1999:35:135-43.

70. Nestor KE, Bacon WL. Divergent selection for body weight and yolk precursor in Coturnix coturnix japonica. 3. Correlated responses in mortality, reproduction traits, and adult body weight. Poult Sci. 1982;61:2137-42.

71. Djawdan M, Sugiyama TT, Schlaeger LK, Bradley TJ, Rose MR. Metabolic aspects of the trade-off between fecundity and longevity in Drosophila melanogaster. Physiol Zool. 1996;69:1176-95.

72. Wilder SM, Raubenheimer D, Simpson SJ. Moving beyond body condition indices as an estimate of fitness in ecological and evolutionary studies. FunctionalEcology. 2016;30:108-15.

73. Schluter D, Gustafsson L. Maternal inheritance of condition and clutch size in the collared flycatcher. Evolution. 1993:47:658-67.

74. Williams TD. Intra-and inter-individual variation in reproductive effort in captive-breeding zebra finches (Taeniopygia guttata). Can J Zool. 1996;74:85-91

75. Phillips RA, Furness RRW. Repeatability of breeding parameters in Arctic skuas. J Avian Biol. 1998;29:190-6.

76. Kvalnes T, Ringsby TH, Jensen H, Sæther B-E. Correlates of egg size variation in a population of house sparrow passer domesticus. Oecologia. 2013;171:391-402.

77. Monaghan P, Nager RG, Houston DC. The price of eggs: increased investment in egg production reduces the offspring rearing capacity of parents. Proc R Soc Lond B. 1998;265:1731-5.

78. Veasey JS, Houston DC, Metcalfe NB. A hidden cost of repreoduction: the trade-offs between clutch size and escape take-off speed in female zebra finches. J Anim Ecol. 2001;70:20-4.

79. Kalmbach E, Griffiths R, Crane JE, Furness RW. Effects of experimentally increased egg production on female body condition and laying dates in the great skua Stercorarius skua. J Avian Biol. 2004;35:501-14.
80. Swaddle JP, Biewener AA. Exercise and reduced muscle mass in starlings. Nature. 2000;406:585-6.

81. Bolton M, Monaghan P, Houston DC. An improved technique for estimating pectoral muscle protein condition from body measurements of live gulls. Ibis. 1991;133:264-70.

82. Selman $\mathrm{RG}$, Houston DC. A technique for measuring lean pectoral muscle mass in live small birds. Ibis. 1996;138:348-50.

83. Bauchinger U, McWilliams SR, Kolb H, Popenko VM, Price ER, Biebach H. Flight muscle shape reliably predicts flight muscle mass of migratory songbirds: a new tool for field ornithologists. J Ornithol. 2011;152:507-14.

84. Vézina F, Williams TD. Interaction between organ mass and citrate synthase activity as an indicator of tissue maximal oxidative capacity in breeding european starlings: implications for metabolic rate and organ mass relationships. Funct Ecol. 2005;19:1 19-28.

85. Houston DC, Donnan D, Jones $P$. The sources of nutrients required for egg production in zebra finches Poephila guttata. J Zool. 1995;235:469-83.

86. Martin TE. Avian life-history evolution has an eminent past: Does it have a bright future? Auk. 2004;121:289.

87. Giordano M, Costantini D, Pick JL, Tschirren B. Female oxidative status, egg antioxidant protection and eggshell pigmentation: a supplemental feeding experiment in great tits. Behav Ecol Sociobiol. 2015;69:777-85.

88. Hamel S, Côtê SD, Festa-Bianchet M. Maternal characteristics and environment affect the costs of reproduction in female mountain goats. Ecology. 2010;91:2034-43.

89. Martin JGA, Festa-Bianchet M. Bighorn ewes transfer the costs of reproduction to their lambs. Am Nat. 2010;176:414-23.

90. Knowles SCL, Nakagawa S, Sheldon BC. Elevated reproductive effort increases blood parasitaemia and decreases immune function in birds: a meta-regression approach. Funct Ecol. 2009;23:405-15.

91. Kotrschal A, Rogell B, Bundsen A, Svensson B, Zajitschek S, Bräannström I, Immler S, Maklakov AA, Kolm N. Artificial selection on relative brain size in the guppy reveals costs and benefits of evolving a larger brain. Curr Biol. 2013;23:168-71.

92. Giordano M, Costantini D, Tschirren B. Sex-specific effects of prenatal and postnatal nutritional conditions on the oxidative status of great tit nestlings. Oecologia. 2015;177:123-31.

\section{Submit your next manuscript to BioMed Central and we will help you at every step:}

- We accept pre-submission inquiries

- Our selector tool helps you to find the most relevant journal

- We provide round the clock customer support

- Convenient online submission

- Thorough peer review

- Inclusion in PubMed and all major indexing services

- Maximum visibility for your research

Submit your manuscript at www.biomedcentral.com/submit
(O) BioMed Central 